\title{
Steam reforming of methane in a bench-scale membrane reactor at realistic working conditions
}

\author{
Marija Saríc \\ Yvonne C. van Delft \\ Raghavendra Sumbharaju \\ Dick F. Meyer \\ Arend de Groot
}




\title{
Steam reforming of methane in a bench-scale membrane reactor at realistic working conditions
}

\author{
Marija Sarić*, Yvonne C. van Delft, Raghavendra Sumbharaju, Dick F. Meyer, Arend de Groot \\ Energy Research Centre of the Netherlands, P.O. Box 11755 ZG, Petten, The Netherlands
}

\section{A R T I C L E I N F O}

\section{Article history:}

Received 13 September 2011

Received in revised form 15 March 2012

Accepted 3 April 2012

Available online $\mathrm{xxx}$

\section{Keywords:}

Membrane reactor

Palladium membranes

Hydrogen

Methane steam reforming

\begin{abstract}
A B S T R A C T
In this study, a bench-scale Pd membrane reactor was used to carry out the methane steam reforming reaction under realistic operating conditions: $580^{\circ} \mathrm{C}, 28 \mathrm{bar}(\mathrm{a})$ and GHSV values up to $950 \mathrm{~h}^{-1}$. The continuous withdrawal of the $\mathrm{H}_{2}$ product resulted in a maximum $\mathrm{CH}_{4}$ conversion of $98 \%$ and a $\mathrm{H}_{2}$ production rate of $0.13 \mathrm{~N} \mathrm{~m}^{3} \mathrm{~h}^{-1}$. A continuous methane conversion of $86 \%$ and a hydrogen flux of $0.1 \mathrm{~mol} \mathrm{~m}^{-2} \mathrm{~s}^{-1}$ were achieved in the membrane reactor under these challenging conditions for almost $1100 \mathrm{~h}$, demonstrating the great potential of membrane reformers for $\mathrm{H}_{2}$ production.
\end{abstract}

(C) 2012 Elsevier B.V. All rights reserved.

\section{Introduction}

Hydrogen, one of the possible energy carriers of the future, is commonly produced through steam reforming of methane (SMR):

$\mathrm{CH}_{4}+\mathrm{H}_{2} \mathrm{O} \leftrightarrow \mathrm{CO}+3 \mathrm{H}_{2}$

And water gas shift reaction:

$\mathrm{CO}+\mathrm{H}_{2} \mathrm{O} \leftrightarrow \mathrm{CO}_{2}+\mathrm{H}_{2}$

Steam reformers are fed with a mixture of natural gas and steam at high temperature. Steam reforming is an endothermic thermodynamic equilibrium reaction, requiring high temperatures to reach high conversions. An $80 \%$ conversion of methane at a temperature of $850^{\circ} \mathrm{C}$ and a pressure of $35 \mathrm{bar}$ is commonly reached with steam to carbon (S/C) ratios in the range of 3-4 [1]. In principle, the selective removal of hydrogen from the reaction zone enables a higher methane conversion even at lower temperatures. This principle has been experimentally confirmed in the case of palladium-based membranes [2-12].

The overall performance of a packed-bed membrane reactor is not dependent on the $\mathrm{H}_{2}$ permeation rate of the membrane used; the basic requirement for a major increase in the reaction rate is that the $\mathrm{H}_{2}$ production rate is in the same order of magnitude as the $\mathrm{H}_{2}$ permeation rate of the membrane. In other words, the rate

Abbreviations: GHSV, gas hourly space velocities; H/C, hydrogen to carbon ratio; SMR, steam-methane reforming; S/C, steam to carbon ratio.

* Corresponding author.

E-mail address: saric@ecn.nl (M. Sarić). of hydrogen production generated in a given volume of the packedbed must balance the permeation rate through the membrane area in the same volume. In addition, it is of importance to perform experiments at high gas hourly space velocities (GHSV) preferably close to the ones used in industrial applications. Typical values of GHSV in industry range from 2000 to $7000 \mathrm{~kg}^{-1} \mathrm{~h}^{-1}$ [1].

In most literature on the membrane-assisted steam reformers, high methane conversions have been achieved, but at a low GHSV $[5,12]$ typically $500 \mathrm{l} \mathrm{kg}^{-1} \mathrm{~h}^{-1}$. The importance of matching product generation and removal was noted by Tong and Matsumura [11]. Their experiments were performed with 8 and $11 \mu \mathrm{m}$ thick membranes with a commercially available alumina-supported nickel catalyst at GHSV in the range $400-20001 \mathrm{~kg}^{-1} \mathrm{~h}^{-1}$. In the experiments with a GHSV of $11201 \mathrm{~kg}^{-1} \mathrm{~h}^{-1}$, methane conversions higher than $70 \%$ were measured. However, it was observed that under the same operating conditions the methane conversion was similar for both membranes. It was concluded that in membrane reactor used with the $8 \mu \mathrm{m}$ thick membrane, the rate limiting step was hydrogen production within the catalyst bed. In addition, the influence of feed flow on conversion was investigated; increasing GHSV led to decreasing methane conversion. The commercially available catalyst used in that study was designed for SMR at temperatures of $850^{\circ} \mathrm{C}$. The adaptability of this catalyst for use at lower temperatures is still not clear and needs further investigation. Methane conversions higher than $89 \%$ are reported for a membrane steam reformer with GHSV of $40001 \mathrm{~kg}^{-1} \mathrm{~h}^{-1}$ at $500^{\circ} \mathrm{C}$ [3].

Recently, literature on Pd-membrane reactors for pure hydrogen production for fuel cell applications has been published [13,14]. The focus was at the production of a high purity, COx-free hydrogen stream. Although this work was performed at low pressures, 


\section{Nomenclature \\ Fi molar flow of component $i\left[\mathrm{~mol} \mathrm{~s}^{-1}\right]$ \\ GHSV gas hour space velocity, flow of methane over the loaded catalyst weight $\left[1 \mathrm{~h}^{-1} \mathrm{~kg}_{\mathrm{cat}}{ }^{-1}\right]$}

interesting hydrogen conversion rates were reported. Methane conversions of $50 \%$ were obtained with a 2 bar pressure difference over the membrane.

In this study a $3.8 \mu \mathrm{m}$ thick Pd membrane and a Ni-based catalyst more suitable for lower operating temperatures were used. The main objective of the current work is to investigate longterm membrane reactor performance with an in-house produced hydrogen-selective Pd membrane under relevant industrial conditions, i.e. at moderate temperature, high pressure and high gas hour space velocity.

\section{Experimental}

\subsection{Component selection}

A palladium membrane $\left(155 \mathrm{~cm}^{2}\right.$, membrane length $35.1 \mathrm{~cm}$ and diameter $1.4 \mathrm{~cm}$ ) was made by electroless plating [15] on commercially available alumina support having an additional intermediate layer as described in [16]. The membrane thickness was measured with Scanning Electron Microscopy (SEM) and was found to be $\sim 3.8 \mu \mathrm{m}$. The membrane was mounted with low pressure compression seals [17] in the test-rig. A nickel-based pre-commercial catalyst (Sudchemie) was used for the membrane reactor experiments.

\subsection{Test equipment}

A simplified flow sheet of the high-pressure (up to 70 bar), high temperature (up to $600^{\circ} \mathrm{C}$ ) facility for testing under realistic process conditions is shown in Fig. 1. The facility contains a single-tube membrane reactor. The maximum membrane length that can be placed in the reactor is $40 \mathrm{~cm}$.

The catalyst is placed in the annulus between the outside of the tubular membrane and the inside of the reactor with inner diameter of $26.2 \mathrm{~cm}$. The feed is first passed over a catalyst packed-bed that serves to already convert part of the feed into syngas. The mixture then enters the annulus where the catalytic steam reforming reaction proceeds in parallel with the removal of $\mathrm{H}_{2}$ by the membrane. The non-permeated gasses leave the reactor as the retentate. Cocurrent sweep is introduced inside the membrane through a central tube.

The reactor is placed in an electrically heated oven. Feed and sweep gasses are supplied through mass flow controllers and are preheated before entering the reactor. Retentate and permeate compositions are analysed with a micro-gas chromatograph (Varian $3600 \mathrm{GC}$ ).
Table 1

Membrane reactor tests conditions.

\begin{tabular}{|c|c|c|}
\hline Test goal & $\begin{array}{l}\text { Gas mixture } \mathrm{N}_{2} / \mathrm{H}_{2} \mathrm{O} / \\
\mathrm{CH}_{4}[\mathrm{~mol} \%]\end{array}$ & Exp. conditions \\
\hline \multirow{5}{*}{$\begin{array}{l}\text { Screening } \\
\text { experiments }\end{array}$} & Mixture $1: 43 / 43 / 14$ & Feed flow dry $[\mathrm{N} l / \mathrm{min}]: 1$ and 3 \\
\hline & Mixture 2: 56/40/4 & GHSV $\left[1 \mathrm{~h}^{-1} \mathrm{~kg}_{\mathrm{cat}}{ }^{-1}\right]=760,950$ \\
\hline & & $\mathrm{N}_{2}$ sweep flow [ $\left.\mathrm{N} 1 / \mathrm{min}\right]: 0.05$ \\
\hline & & $p_{\text {feed }}[\mathrm{bar}]=25-38$ \\
\hline & & $\begin{array}{l}p_{\text {sweep }}[\mathrm{bar}]=1 \\
T\left[{ }^{\circ} \mathrm{C}\right]=550-600\end{array}$ \\
\hline \multirow{6}{*}{$\begin{array}{l}\text { Long duration } \\
\text { tests }\end{array}$} & Mixture 1 & Feed flow dry [N $1 / \mathrm{min}]: 3$ \\
\hline & & GHSV $\left[\mathrm{kg} \mathrm{h}^{-1} \mathrm{l}^{-1}\right]=950$ \\
\hline & & $\mathrm{N}_{2}$ sweep flow [ $\left.\mathrm{Nl} / \mathrm{min}\right]: 0.05$ \\
\hline & & $p_{\text {feed }}[\mathrm{bar}]=26$ \\
\hline & & $p_{\text {sweep }}[\mathrm{bar}]=1$ \\
\hline & & $T\left[{ }^{\circ} \mathrm{C}\right]=550$ \\
\hline \multirow{5}{*}{$\begin{array}{l}\text { Optimization at } \\
\text { highest GHSV }\end{array}$} & Mixture 1 & Feed flow dry $[\mathrm{N} 1 / \mathrm{min}]: 3$ \\
\hline & & GHSV $\left[1 \mathrm{~h}^{-1} \mathrm{~kg}_{\mathrm{cat}}{ }^{-1}\right]=950$ \\
\hline & & $\begin{array}{l}p_{\text {sweep }}[\mathrm{bar}]=1 \\
T\left[{ }^{\circ} \mathrm{C}\right]=550\end{array}$ \\
\hline & & $\mathrm{N}_{2}$ sweep flow $[\mathrm{N} 1 / \mathrm{min}]: 0.05,0.1$ \\
\hline & & $p_{\text {feed }}[\mathrm{bar}]=5-26$ \\
\hline
\end{tabular}

\subsection{Description of the experiments}

In order to prevent the influence of catalyst deactivation on the methane conversion, the methane reforming experiments were performed with an excess of catalyst. The amount of catalyst used in experiments was $195.5 \mathrm{~g}(160 \mathrm{ml})$, while calculations reveal that the activity only becomes limiting below $3 \mathrm{~g}$. These calculations were performed using the model presented in [18] and for the experimental conditions given in Table 1.

In screening experiments, the effect of the feed flow and composition, the feed pressure and operating temperature on $\mathrm{CH}_{4}$ conversion was determined. The membrane selectivity performance was monitored through single gas permeation measurements with pure $\mathrm{H}_{2}$ and $\mathrm{N}_{2}$ between membrane reactor experiments. Subsequently, the duration tests were performed with a fixed feed composition and fixed flow for almost $1100 \mathrm{~h}$. The reactor performance was determined at regular intervals.

Finally, the conversion was optimized at the highest GHSV with respect to the two membrane operating variables: feed pressure and sweep flow rate.

Between the long duration experiments and optimization experiments the membrane reformer was kept for four days in a nitrogen atmosphere. The conditions of experiments are given in Table 1.

The membrane selectivity was calculated by comparing the measured fluxes from the single gas permeation measurements. These measurements were performed for hydrogen and nitrogen at the same feed and permeate pressure.

The hydrogen recovery was calculated with following equation:

$X_{\mathrm{H}_{2} \text { rec. }}=\frac{F_{\mathrm{H}_{2} \text {, permeate }}}{4 \cdot\left(F_{\mathrm{CH}_{4} \text {, feed }}-F_{\mathrm{CH}_{4} \text {, retenate }}\right)} \cdot 100$

The $\mathrm{CH}_{4}$ conversion was calculated in the case of membrane reforming with:

$$
X_{\mathrm{CH}_{4}}=\left(\frac{F_{\mathrm{CO}_{2} \text {, retentate }}+F_{\mathrm{CO}, \text { retentate }}+F_{\mathrm{CO}_{2} \text {, permeate }}+F_{\mathrm{CO} \text {, permeate }}}{F_{\mathrm{CH}_{4} \text {, feed }}}\right) \cdot 100
$$

The hydrogen purity is calculated using this equation:

$$
\mathrm{H}_{2} \text { purity }=\left(\frac{F_{\mathrm{H}_{2} \text {, permeate }}}{F_{\mathrm{H}_{2}} \text {, permeate }+F_{\mathrm{CH}_{4}} \text {, permeate }+F_{\mathrm{CO}_{2} \text {, permeate }}+F_{\mathrm{CO}} \text {, permeate }+F_{\mathrm{N}_{2}} \text {, permeate }-F_{\mathrm{N}_{2}} \text {, sweep }}\right) \cdot 100
$$




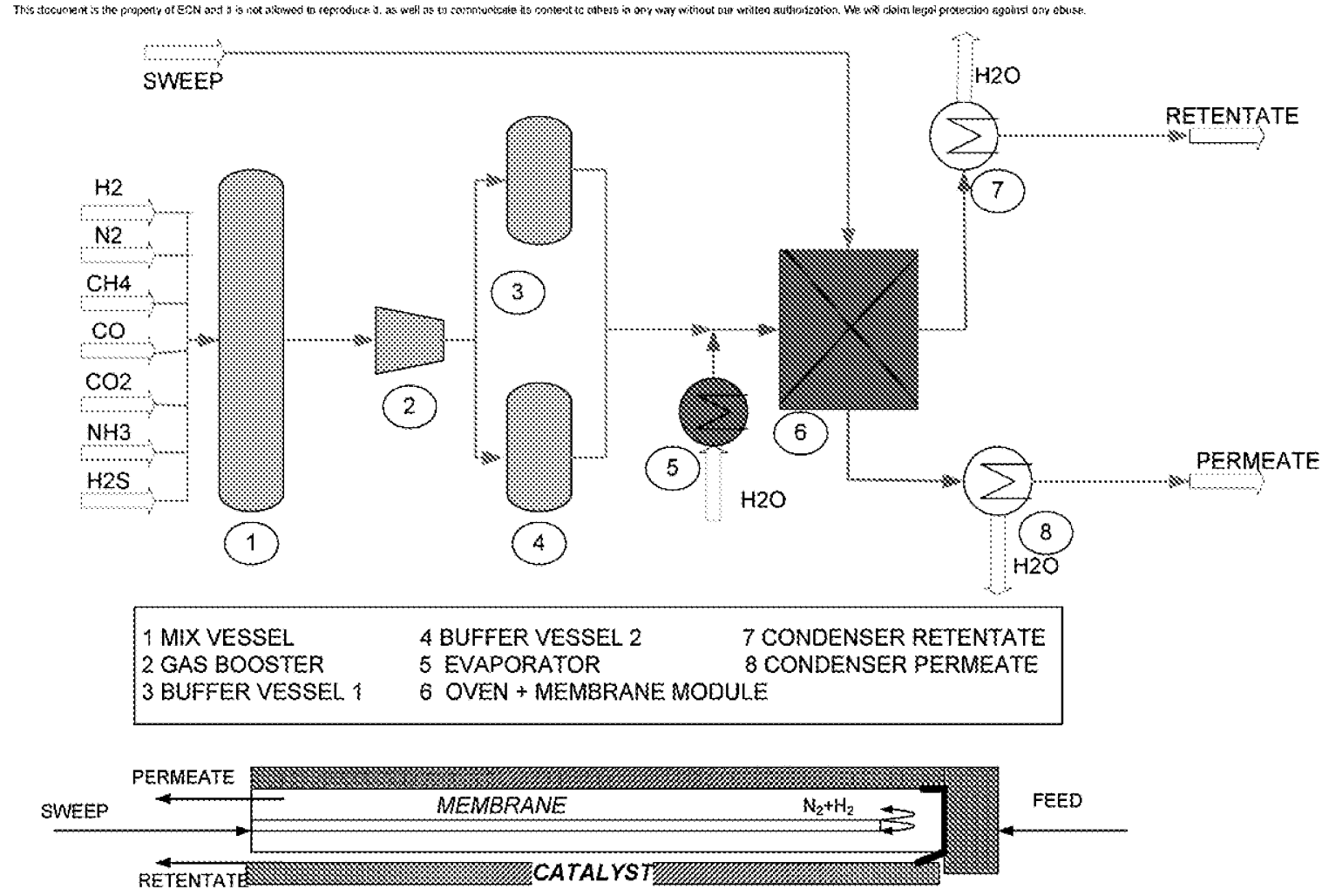

Fig. 1. Simplified flowsheet of the membrane reactor test-unit (above), and membrane module (below).

The thermodynamic equilibrium conversion was calculated using the Gibbs reactor model from the Aspen Plus simulation program.

\section{Results and discussion}

\subsection{Membrane performance}

The initial membrane and seal qualities were checked with single gas hydrogen and nitrogen permeance tests after mounting the membrane into the module. The resulting $\mathrm{N}_{2}$ permeance was too low to be accurately determined and the membrane $\mathrm{H}_{2} / \mathrm{N}_{2}$ selectivity was estimated to be over 1800 at 6 bar feed pressure. From this it can be concluded that membrane was leak tight. The measured hydrogen flux was $1.7 \mathrm{~mol} \mathrm{~m}^{-2} \mathrm{~s}^{-1}$ at $525^{\circ} \mathrm{C}$ and a pressure difference of 4.8 bar. Fig. 2 shows that the hydrogen permeance value obtained in this work is high in comparison with literature values determined under comparable conditions $[3,19]$.

After the duration experiments single gas hydrogen and nitrogen permeance tests were performed and the measured $\mathrm{H}_{2} / \mathrm{N}_{2}$ selectivity was 97 at 5.2 bar feed pressure, 4.18 bar pressure difference and temperature of $600^{\circ} \mathrm{C}$. Thus, the selectivity of the membrane decreased at least 18 times after testing for $1100 \mathrm{~h}$.

\subsubsection{Screening experiments}

Steam reforming is an endothermic reaction in the gas phase in which the number of moles increases with reaction. This means that this reaction will be favoured at high temperatures and at lower feed pressures.

To increase the hydrogen recovery in the membrane reactor a high hydrogen flux over the membrane is required, so operation at a high feed temperature and pressure is favourable. The operation at the high pressure is contrary to the reaction demand. Moreover, at high pressure the hydrogen purity will decrease because the flux of other components that are permeating over membrane by Knudsen or viscous flow will also increase.

There are also two counteracting effects that need to be balanced in selecting the operating temperature of the membrane reactor:

- Component permeation is favoured at higher temperature because of the Arrhenius temperature dependency

- Membrane life time decreases with higher temperature due to higher possibility for occurring of the leak flow over the sealing.

Table 2 shows that the maximum obtained methane conversion was $98 \%$ at $p_{\text {feed }}=28$ bar, $T=580^{\circ} \mathrm{C}$ and a GHSV equal to $7601 \mathrm{~h}^{-1} \mathrm{~kg}_{\text {cat }}{ }^{-1}$. The hydrogen recovery and purity at these

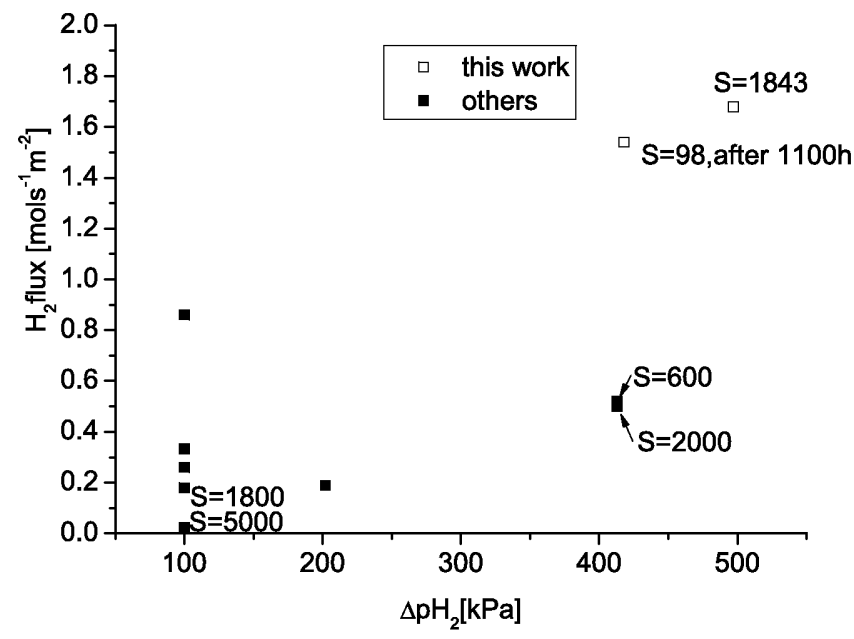

Fig. 2. Measured hydrogen flux in various literature and in this work vs. the pressure difference at $S=$ selectivity, if not mentioned in figure selectivity was high $[3,19]$ Temperature was in range $T=525 \pm 25^{\circ} \mathrm{C}$. 
Table 2

Preliminary experimental results, $T=560 \pm 20^{\circ} \mathrm{C}$.

\begin{tabular}{llllll}
\hline Time $[\mathrm{h}]$ & $\begin{array}{l}\mathrm{GHSV} \\
{\left[1 \mathrm{~h}^{-1} \mathrm{~kg}_{\text {cat }}{ }^{-1}\right]}\end{array}$ & $\begin{array}{l}p_{\text {feed }} \\
{[\mathrm{bar}]}\end{array}$ & $X_{\mathrm{CH}_{4}}$ & $X_{\mathrm{H}_{2} \text { rec }}$ & $\mathrm{H}_{2}$ purity \\
\hline 118.8 & 950 & 35 & 75.3 & 64.5 & 82.6 \\
145.2 & 760 & 28 & 98.5 & 66.2 & 91.1 \\
147.12 & 760 & 42 & 96.1 & 87.8 & 86.5 \\
236.64 & 950 & 24 & 89.8 & 69.4 & 90.5 \\
242.64 & 950 & 25 & 91 & 71.4 & 90.7 \\
261.12 & 950 & 24 & 90.0 & 71.6 & 90.3 \\
284.16 & 950 & 25 & 89.3 & 67.9 & 89.8 \\
\hline
\end{tabular}

conditions were respectively 66 and $92 \%$ (with $8.70 \% \mathrm{CO}_{2}$, $0.03 \mathrm{~mol} \% \mathrm{CO}$ and $0.18 \mathrm{~mol}^{\circ} \mathrm{CH}_{4}$ on the dry basis). As expected a lower feed pressure leads to a lower hydrogen recovery with a higher purity. For example, in experiments with the GHSV of $7601 \mathrm{~h}^{-1} \mathrm{~kg}_{\mathrm{cat}}{ }^{-1}$ the hydrogen recovery increases from 66 to $88 \%$, while purity decreased from 92 to $86 \%$ when the feed pressure is increased from 28 to 42 bar. Since the methane conversion also depends on the feed pressure, a balance between methane conversion, hydrogen recovery and purity has to be found.

For the long duration test the optimum conditions to balance those factors were selected.

A GHSV of $9501 \mathrm{~h}^{-1} \mathrm{~kg}_{\mathrm{cat}}{ }^{-1}$ was selected [1]. A feed pressure of 26 bar was selected to favour the methane conversion and intermediate temperature of $550^{\circ} \mathrm{C}$ was chosen as a compromise between hydrogen permeation and membrane life time expectations.

\subsubsection{Long duration tests}

Fig. 3 shows that the membrane reactor had a stable performance in the long duration tests with an average methane conversion of $\sim 86 \%$. The obtained hydrogen recovery in these experiments was $\sim 70 \%$ and hydrogen purity was higher than $80 \%$. The hydrogen purity decreases with time.

More data on catalyst post-analysis performed after these experiments can be found in recent literature [18]. Pieterse et al. [18] reported that the significant amount of carbon deposition was found after these membrane reactor tests. However, it is suspected that in the time-span of the experiments the effect of C-deposition on the catalyst activity can be masked by the over dimensioned catalyst amount. Thus, the decrease of the hydrogen purity in the experiments is probably not caused by catalyst deactivation.

Possible reason for hydrogen purity decrease is an increase of the leak flow. This was confirmed with single gas measurements

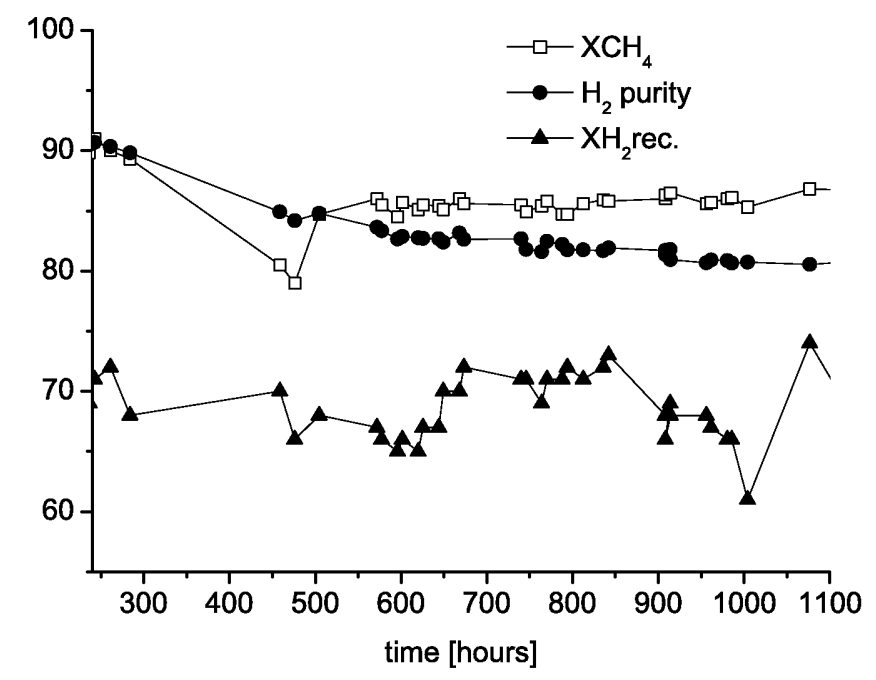

Fig. 3. Measured methane conversion, hydrogen purity and hydrogen recovery in the long duration membrane reformer experiments for conditions in Table 1.

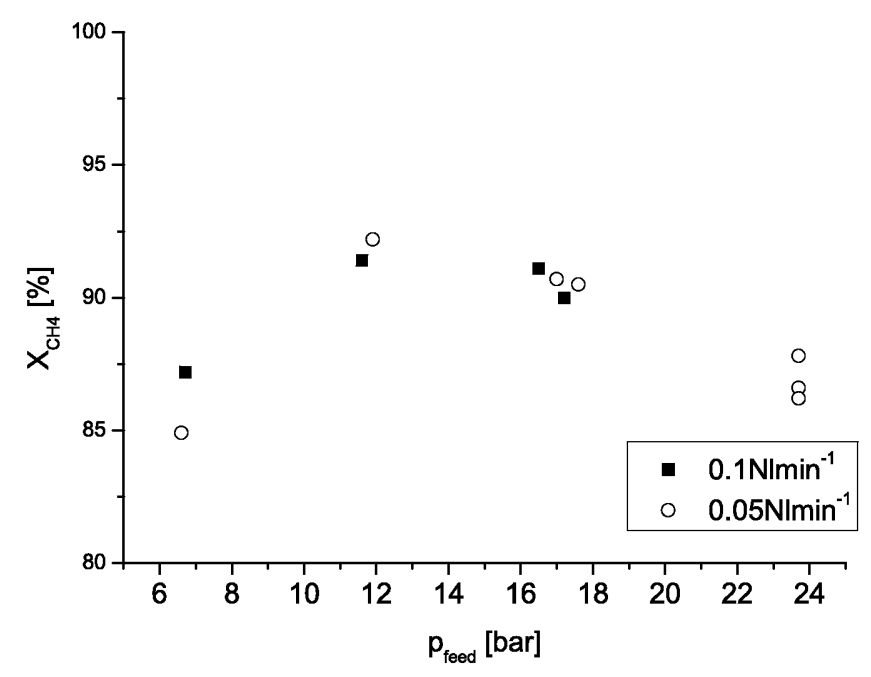

Fig. 4. Conversion vs. feed pressure for different sweep flows at $550 \pm 20^{\circ} \mathrm{C}$ and GHSV $=950 \mathrm{l} \mathrm{h}^{-1} \mathrm{~kg}_{\mathrm{cat}}{ }^{-1}$.

performed after the long duration tests in which it was found that the membrane selectivity decreased 18 times. More detailed analysis of the permeate composition showing decrease in hydrogen purity and fluxes of permeating compounds during these tests are given in Figs. 6 and 7. Fig. 7 shows that the hydrogen and methane fluxes were constant in the long duration experiments while the $\mathrm{CO}_{2}$ and $\mathrm{CO}$ flux increased indicating increase in the leak flow. Since the $\mathrm{CO}_{2}$ is also product of the reaction it is expected that because $\mathrm{CO}_{2}$ flux increases during the long duration experiments, while the $\mathrm{CH}_{4}$ and $\mathrm{H}_{2}$ fluxes are constant, the methane conversion will also increase. However, Fig. 3 shows that the methane conversion in long duration experiments is not affected by the increase in the leak flow. This can be explained by the possible position of the leak. If the leak is positioned at the sealing where feed leaves the membrane, the methane conversion will not be affected by increase of the leak flow.

\subsubsection{Optimization of the methane conversion}

Fig. 4 shows the results of variations in feed pressure and sweep flow rate with the aim to increase the conversion above the target of $90 \%$ at the highest GHSV. A maximum conversion of $92 \%$ was found at a feed pressure of 12 bar, which was slightly higher than in the screening experiments at the same GHSV. At lower feed pressures the flux of hydrogen through the membrane was lower and thus the hydrogen removal was limiting. Increased pressure causes the equilibrium partial pressure of $\mathrm{H}_{2}$ within the catalyst bed to decrease. No influence of the sweep flow was found, meaning that the sweep side mass transfer for hydrogen transport in the membrane reactor was not the rate limiting step.

\subsubsection{Comparison of membrane reactor with equilibrium conversion}

Fig. 5 compares the equilibrium with the experimentally obtained $\mathrm{CH}_{4}$ conversion. The equilibrium conversion decreased as expected with a pressure increase and increased with a temperature increase. In the membrane reactor the conversion can both decrease or increase with increase in the feed pressure.

From the figure it can be noticed that calculated equilibrium conversion for two experimental conditions at $150-200 \mathrm{~h}$ was higher than for other experimental conditions. The reason for this is that these two experiments were performed with higher $\mathrm{N}_{2}$ dilution (Mixture 2 in Table 1 ). Since the $\mathrm{N}_{2}$ dilution for Mixture 2 is $56 \%$ compared to $43 \%$ for Mixture 1, the partial pressures of steam 


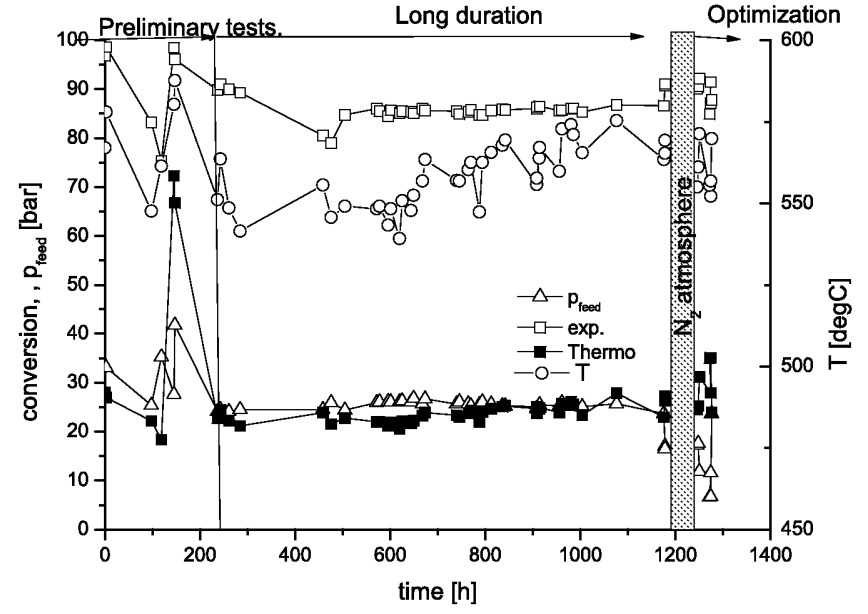

Fig. 5. Experimental (Exp.) vs. equilibrium conversion (Thermo.) at $550 \pm 30^{\circ} \mathrm{C}$.

and methane were lower for Mixture 1, resulting in a higher thermodynamic methane conversion for Mixture 2 .

Fig. 5 shows that in the membrane reactor a maximum methane conversion of $98 \%$ was achieved compared to the equilibrium conversion of $26 \%$. Thus, the maximum increase of methane conversion due to performing reaction in the membrane reactor was $72 \%$.

\subsubsection{Membrane selectivity and hydrogen flux}

The permeate stream composition, after substracting the nitrogen sweep, is presented in Fig. 6. The hydrogen purity in the experiments was always higher than $80 \%$, depending on the feed pressure, with a maximum of $95 \%$.

The measured amount of $\mathrm{CO}$ in the permeate was in all cases lower than $\sim 150 \mathrm{ppm}$, while the $\mathrm{CO}_{2}$ content in the permeate reached rather high values of $\sim 13 \%$. The measured amount of $\mathrm{CH}_{4}$ in the permeate side was $2.5 \mathrm{~mol} \%$.

In the long duration experiments, the $\mathrm{CO}_{2}$ content increases from $11 \mathrm{~mol} \%$ to $15 \mathrm{~mol} \%$, and $\mathrm{CO}$ content increases from 71 to $129 \mathrm{ppm}$ with time. The $\mathrm{CH}_{4}$ content at the permeate side was rather constant, while $\mathrm{H}_{2}$ content decreased with time.

The reason that $\mathrm{CO}_{2}$ permeates so much while the $\mathrm{CO}$ content stays rather low can be explained by withdrawal of hydrogen from the thermodynamic equilibrium mixture that contains low $\mathrm{CO}$ amount. At the operating condition of the long duration experiments ( 26 bar, $T=580^{\circ} \mathrm{C}$ and mixture composition given in Table 1) gas at the thermodynamic equilibrium contains $0.44 \% \mathrm{CO}, 4.60 \%$

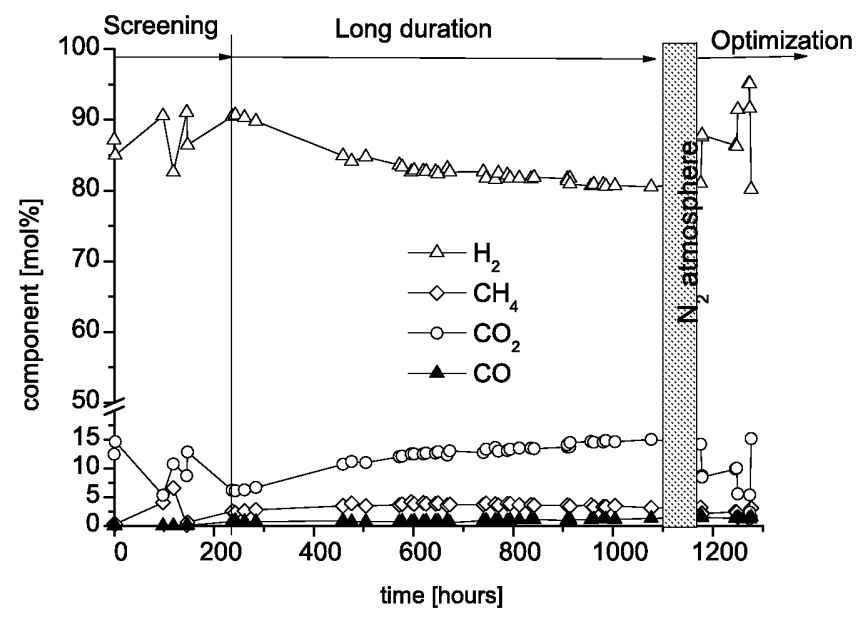

Fig. 6. Composition of the permeate stream without the nitrogen sweep with conditions given in Table 1 .

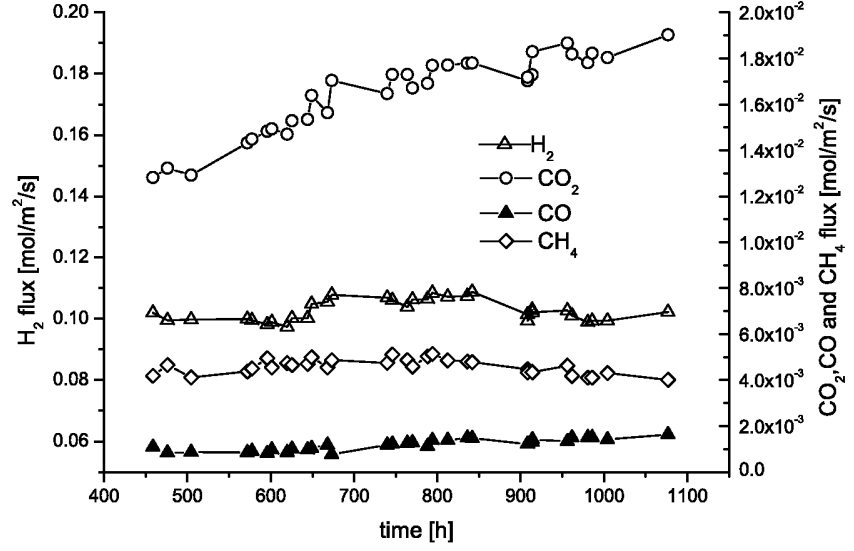

Fig. 7. The $\mathrm{CO}, \mathrm{CO}_{2}, \mathrm{H}_{2}$ and $\mathrm{CH}_{4}$ flux in the long duration experiments.

$\mathrm{CO}_{2}, 17.88 \% \mathrm{CH}_{4}, 19.73 \% \mathrm{H}_{2}$ and $57.34 \% \mathrm{H}_{2} \mathrm{O}$. The calculated fluxes for different components permeating membrane in the long duration experiments are presented in Fig. 7.

This figure shows that $\mathrm{CO}_{2}$ and $\mathrm{CO}$ flux increased with time, confirming the increase in the leak flow. The $\mathrm{H}_{2}$ and $\mathrm{CH}_{4}$ flux were constant with time. As measured selectivity at the end of these experiments was 98 , it is expected that hydrogen flux will remain the same in the long duration experiments because contribution of the leak to the total hydrogen flux is small. Since in the long duration experiments the measured methane conversion was the same, while the leak flow increased it is expected that also methane flux will increase in time. However, the calculated methane flux was rather constant. There is no apparent or obvious reason why the flux remained constant.

Fig. 8 shows the hydrogen flux through the membrane in the reactor as a function of the hydrogen partial pressure drop $\left(\Delta p_{\mathrm{H}_{2}}\right)$ over the membrane: the driving force. This value is calculated from the average of the hydrogen partial pressure differences at the membrane reactor inlet and the outlet. For the calculation of the inlet $\mathrm{H}_{2}$ partial pressure the thermodynamic conversion of the feed was assumed. This is fairly good assumption because of the fast steam reforming kinetics and the fact that in the used configuration the feed is first let over a packed bed of catalyst without membrane (see Fig. 1).

Fig. 7 shows that the measured hydrogen flux was in range of $0.08-0.12 \mathrm{~mol} \mathrm{~m}^{-2} \mathrm{~s}^{-1}$. As expected the flux decreases with a decrease in the driving force. The measured flux in pure hydrogen

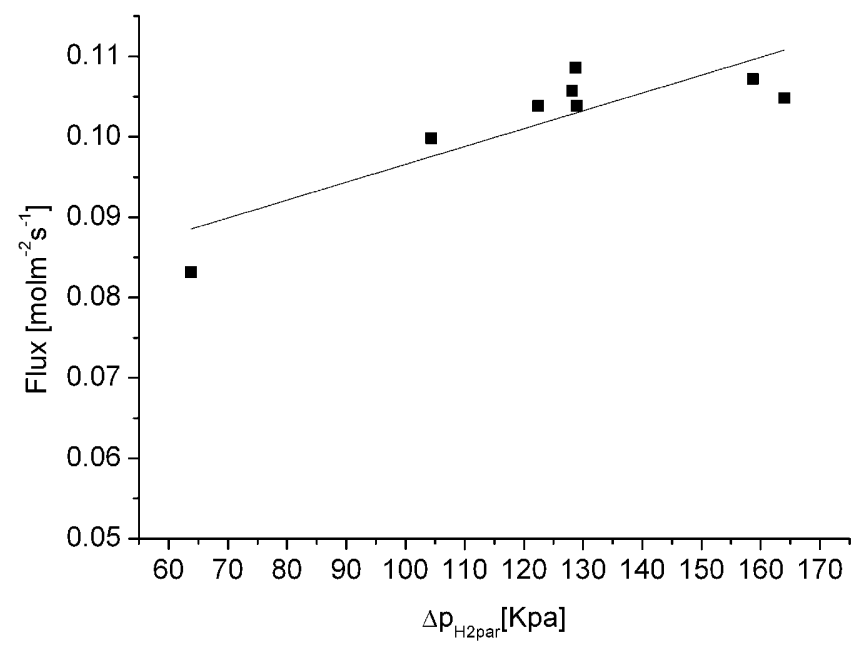

Fig. 8. Measured hydrogen flux vs. driving force $T=550 \pm 20^{\circ} \mathrm{C}$, dots - experimental, line - linear fit. 
measurement was $1.7 \mathrm{~mol} \mathrm{~m}^{-2} \mathrm{~s}^{-1}$ at $525^{\circ} \mathrm{C}$ and a pressure difference of 4.8 bar.

If the flux obtained in membrane reactor experiments is linearly extrapolated to a value of the driving force for the pure hydrogen measurements, the calculated hydrogen flux is approximately 6 times lower than the measured pure hydrogen flux. For this extrapolation it was assumed that the pressure exponent for hydrogen permeation is equal to 1 . This is a fairly good assumption since the membrane thickness was estimated at $3.8 \mu \mathrm{m}$ and for such thin membranes the distance for bulk diffusion will become increasingly short. Thus, the hydrogen transport through the membrane will not be governed by Sieverts' law that gives a pressure exponent of 0.5 but by the other processes such as surface effects, gaseous flow through defects, or transport resistance through the substrate [20] that gives a pressure exponent of 1.0.

The lower value of hydrogen flux measured in the mixture can be attributed to:

1) Decrease of the hydrogen flux due to adsorption of the other components such $\mathrm{CO}, \mathrm{CO}_{2}$ and $\mathrm{H}_{2} \mathrm{O}$ on the Pd surface

2) Concentration polarization effect $[21,24,28]$.

A number of studies were carried out to determine the effect of the gasses such as $\mathrm{CO}, \mathrm{CO}_{2}$ and $\mathrm{H}_{2} \mathrm{O}$ on the hydrogen flux [22-27]. Sakamoto et al. [22] found that the presence of $\mathrm{CO}$ at the temperatures lower than $500^{\circ} \mathrm{C}$ can significantly decrease the hydrogen flux. At $450{ }^{\circ} \mathrm{C}$ the measured decrease in hydrogen flux was $30 \%$. However, since the operating temperature in our experiments is $100^{\circ} \mathrm{C}$ higher it is expected that the 6 times decrease in flux is not the only result of $\mathrm{CO}$ poisoning. There is some disagreement over the effect of $\mathrm{CO}_{2}$ and $\mathrm{H}_{2} \mathrm{O}$ on hydrogen flux. In some studies it is suggested that these two gases significantly reduce hydrogen flux [25], while in some opposite is claimed [23,24,27].

In the work of Gallucci et al. [28] it was theoretically shown that in the packed bed membrane reactor in the case of membranes with high hydrogen permeation rate the hydrogen transport can be highly limited by concentration polarization effect. For the membranes with high permeation rate it was calculated that hydrogen rate fraction at the membrane decreased approximately 4 times because of the mass transfer limitation of hydrogen transport from the catalyst bed to the membrane. In the work of Peters et al. [24] the extent of permeation reduction as a function of the gas composition, gas velocity, temperature, pressure was determined. It was determined that hydrogen permeance in the water gas shift mixture $\left(60 \% \mathrm{H}_{2}, 19.2 \mathrm{~mol} \% \mathrm{CO}_{2}, 15.4 \% \mathrm{H}_{2} \mathrm{O}, 4 \% \mathrm{CO}\right.$ and $1.2 \%$ $\mathrm{CH}_{4}$ ) decreased $\sim 10$ times compared to pure hydrogen permeance. These experiments were performed with $2 \mu \mathrm{m}$ thick membrane at the feed pressure of $20 \mathrm{bar}$, temperature of $400^{\circ} \mathrm{C}$, linear gas velocity of $0.22 \mathrm{~m} \mathrm{~s}^{-1}$. The major contribution to the hydrogen permeation decrease was attributed to the concentration polarization and the surface effects, where the surface effects are mainly due to $\mathrm{CO}$ adsorption at the surface. Experiments carried out in this work were done at the same linear gas velocities as in Peters et al., feed pressures of 28 bar and temperatures of $550{ }^{\circ} \mathrm{C}$. Since, the contribution of surface effects to the permeation reduction decreases with increase of temperature, it is expected that 6 times permeance reduction calculated in this work can be attributed to the concentration polarization effect.

\section{Conclusions and recommendations}

Membrane reactor experiments were performed at moderate temperature and pressure conditions and with GHSV of typically half of the industrial value. The obtained methane conversion at these conditions was higher than $90 \%$ with high hydrogen purity
(80-95\%) and a reasonably high recovery $60-80 \%$. The maximum obtained methane conversion was $98 \%$ at 28 bar and a temperature of $580^{\circ} \mathrm{C}$. In addition, a stable membrane reactor performance for almost $1100 \mathrm{~h}$ was achieved. The average conversion during this long duration test was $86 \%$. Further, as expected the methane conversion decreased with an increase of the GHSV. To achieve a conversion higher than $90 \%$ for the highest GHSV possible in these experiments, it was determined that the feed pressure needed to be decreased to $10-15$ bar. In the membrane reactor experiments a maximum increase of $72 \%$-points in methane conversion was achieved compared to thermodynamic conversion.

Next to the high hydrogen purity, the CO content measured in the permeate was low and in the range of $59-154 \mathrm{ppm}$. The permeate had $\mathrm{CO}_{2}$ concentration of approximately $12 \%$. This concentration increased in time in the long duration experiments notifying the increase of the leak flow.

In addition to this, the application of this membrane reactor for production of hydrogen rich gas for ammonia production was evaluated. There are two advantages of membrane reactors for ammonia feed production:

1) The energy efficiency of the process can be increased by operating the reactor at the lower temperature.

2) The cost of the syngas production could possibly be decreased due to a reduction in the number of process steps; removal of the hydrogen from the reaction zone in the membrane reactor allows complete methane conversion in one reaction step. The pure hydrogen stream will be withdrawn at the permeate side. In this way it is possible to skip high temperature, low temperature shift reactors and purification steps. However, it should be noted that syngas entering the ammonia synthesis loop has the carbon oxides content less than 50 ppmv [29].

From the obtained experimental results it can be concluded that the measured impurities level in the permeate are not satisfying for production of $\mathrm{H}_{2}$ enriched gas for ammonia production and because of that purification steps such as $\mathrm{CO}_{2}$ removal and methanation cannot be skipped. The further work focusing on the improving of the membrane selectivity and decreasing impurities level in the permeate to the acceptable values is required.

\section{Acknowledgement}

Part of this research was funded by the Dutch Ministry of Economic Affairs via the agency SenterNovem through the EOS-LT program under project number EOSLT05010.

\section{References}

[1] M.V. Twigg, Catalyst Handbook, second ed., Wolfe Publishing Ltd., England, 1989.

[2] M. Chai, M. Machida, K. Equchi, H. Arai, Chemistry Letters 22 (1993) 41-44.

[3] Y. Chen, Y. Wang, H. Xu, G. Xiong, Applied Catalysis B 80 (2008) 283-294.

[4] F. Gallucci, L. Paturzo, A. Fama, A.A. Basile, Ind ustrial and Engineering Chemistry Research 43 (2004) 928-933.

[5] E. Kikuchi, S. Uemiya, T. Matsuda, Natural Gas Conversion 61 (1991) 509-515.

[6] G. Madia, G. Barbieri, E. Drioli, Theoretical and experimental analysis of methane steam reforming in a membrane reactor, Canadian Journal of Chemical Engineering 77 (1999) 698-706.

[7] S.W. Nam, S.P. Yoon, H. Ha, S.A. Hong, A.P. Maganyuk, Korean Journal of Chemistry 17 (2000) 288-291.

[8] M. Oertel, J. Schmitz, W. Weirich, D. Jendryssek-Neumann, R. Schultem, Chemical Engineering and Technology 10 (1987) 248-255.

[9] J. Shu, B.P.A. Grandjean, A. van Neste, S. Kaliaguine, Canadian Journal of Chemical Engineering 69 (1991) 1036-1060.

[10] J. Tong, Y. Matsumura, H. Suda, K. Haraya, Industrial and Engineering Chemistry Research 44 (2005) 1454-1465.

[11] J. Tong, Y. Matsumura, Catalysis Today 111 (2006) 147-152.

[12] S. Uemiya, N. Sato, H. Ando, T. Matsuda, E. Kikuchi, Applied Catalysis 67 (1991) $223-230$. 
[13] A. Iulianelli, G. Manzolini, M. de Falco, S. Campanari, T. Logo, S. Liquori, A. Basile, International Journal of Hydrogen Energy 35 (2010) 11514-11524.

[14] A. Basile, S. Campanari, G. Manzolini, A. Iulianelli, T. Longo, S. Liguori, M. de Falco, V. Piemonte, International Journal of Hydrogen Energy 36 (2011) 11531-11539.

[15] K. Hou, R. Hugues, Journal of Membrane Science 206 (2002) 119-130.

[16] B.C. Bonekamp, A. van Horssen, L.A. Correia, J.F. Vente, W.G. Haije, Journal of Membrane Science 278 (2006) 349-356.

[17] F. Rusting, G. de Jong, P.P.A.C. Pex, J.A.J. Peters, EP1257758 B1 (2001)

[18] J.A.Z. Pieterse, J. Boon, Y.C. van Delft, J.W. Dijkstra, R.W. van den Brink, Catalysis Today 156 (2010) 153-164.

[19] S. Yun, S.T. Oyama, Journal of Membrane Science 375 (2011) 28-45.

[20] K.S. Rothenberger, A.V. Cugini, B.H. Howard, R.P. Killmeyer, M.V. Ciocco, B.D. Morreale, R.M. Enick, F. Bustamante, I.P. Mardilovich, Y.H. Ma, Journal of Membrane Science 244 (2004) 55-68.

[21] Membranes and membrane separation processes, in: Ullmann's Encyclopedia of Industrial Chemistry, Wiley-VCH Verlag GmbH \& Co., 2006.
[22] Y. Sakamoto, F.L. Chen, Y. Kinari, F. Sakamoto, International Journal of Hydrogen Energy 21 (1996) 1017-1024.

[23] A.L. Mejdell, M. Jondahl, T.A. Peters, R. Bredesen, H.J. Venvik, Separation and Purification Technology 68 (2009) 178-184.

[24] T.A. Peters, M. Stange, R. Bredesen, Journal of Membrane Science 316 (2008) $119-127$.

[25] A. Unemoto, A. Kaimai, K. Sato, T. Otake, K. Yashiro, J. Mizusaki, T. Kawada, T. Tsuneki, Y. Shirasaki, I. Yasuda, International Journal of Hydrogen Energy 32 (2007) 4023-4029.

[26] A. Unemoto, A. Kaimai, K. Sato, T. Otake, K. Yashiro, J. Mizusaki, T. Kawada, T. Tsuneki, Y. Shirasaki, I. Yasuda, International Journal of Hydrogen Energy 32 (2007) 2881-2887.

[27] S.H. Israni, M.P. Harold, Industrial and Engineering Chemistry Research 49 (2010) 10242-10250.

[28] F. Gallucci, M. van Sintannaland, J.A.M. Kuipers, International Journal of Hydrogen Energy 35 (2010) 7142-7150.

[29] J.A. Ritter, A.D. Ebner, Separation Science and Technology 42 (2007) 1123-1193.

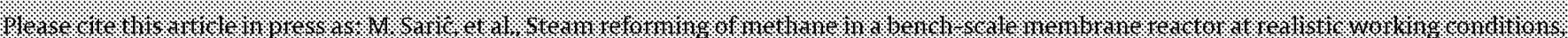

